\title{
Temporal Variability of Primary Production Explains Marine Ecosystem Structure and Function
}

\author{
A. J. Schlenger, ${ }^{1 *}$ S. Libralato, ${ }^{2}$ and L. T. Ballance ${ }^{1,3}$
}

\begin{abstract}
${ }^{1}$ Scripps Institution of Oceanography, University of California San Diego, La Jolla, California 92093-5004, USA; ${ }^{2}$ Oceanography Division, Istituto Nazionale di Oceanografia e di Geofisica Sperimentale - OGS, Via Beirut 2/4 (Ex-Sissa Building), 34151 Trieste, Italy; ${ }^{3}$ Southwest Fisheries Science Center, NOAA Fisheries, La Jolla, California, USA
\end{abstract}

\begin{abstract}
Understanding drivers of ecosystem structure and function is a pervasive goal in academic and applied research. We used 24 synthetic ecosystem-level indices derived from trophic models, and independently derived data for Net Primary Productivity, to investigate drivers of ecosystem structure and function for 43 marine ecosystems distributed in all oceans of the world and including coastal, estuaries, mid-ocean islands, open-ocean, coral reef, continental shelf, and upwelling ecosystems. Of these indices, ecosystem Biomass, Primary Production, Respiration, the ratio of Biomass to Total System Throughput (sum of total energy flow into and out of an ecosystem as well as between ecosystem components), the ratio of Production to Biomass, Residence Time (mean time that a unit of energy remains in the ecosystem), Average Trophic Level, and Relative Ascendency (index of organi-
\end{abstract}

zation and complexity of a food web) displayed relationships with measures of Net Primary Productivity (NPP). Across all ecosystems, relationships were stronger with seasonal and interannual variability of NPP as compared to mean NPP. Both measures of temporal variability were combined into multivariate predictive relationships for each ecosystem index, with $r^{2}$ values ranging from 0.14 to 0.49 and Akaike's information criteria values from -8.44 to 3.26 . Our results indicate that despite large geographic and environmental differences, temporal variability of NPP is strongly linked to the structure and function of marine ecosystems.

Key words: ecosystem modeling; network analysis; Ecopath with Ecosim (EwE); net primary production; energetics; ecology; ecosystems.
Received 23 October 2017; accepted 2 June 2018; published online 18 June 2018

Electronic supplementary material: The online version of this article (https://doi.org/10.1007/s10021-018-0272-y) contains supplementary material, which is available to authorized users.

Authors' Contribution AS sourced data, conducted analysis, and responsible for general writing and reviewer responses. SL provided ecological modeling advise, experimental structure support, and assistance in interpreting results throughout the study as well as direction in writing the manuscript. LB provided ecological advising when setting up study structure and interpretation as well as comprehensive writing guidance and editing.

*Corresponding author; e-mail: aschleng@ucsd.edu

\section{INTRODUCTION}

Ever since the inception of ecology as a field of science, a major challenge has been to understand the drivers of ecosystem structure and function (Levin 1995). Yet due to the sheer magnitude and complexity of ecosystems, the difficulties associated with quantifying all the vital processes of an ecosystem, or with conducting experiments at an ecosystem scale, this goal has remained elusive. The majority of past ecological studies attempt to focus on individual processes or to scale dynamics 
down to manageable scopes (Elton 1930), leading to a wide variety of discoveries that apply to specific circumstances, but lack a consistent mechanistic framework applicable across ecosystems. However, modern advancements in analytical tools and data collection are slowly beginning to overcome the obstacles of complexity and scale (Colléter and others 2015). Ecology has also expanded into a multidisciplinary field over the past few decades, whereby a diverse set of approaches to ecological questions have led to a multitude of new insights and breakthroughs (Irschick and others 2013). These recent developments and additions to ecological thinking have opened the door for scientists to overcome the challenges of scale as well as to create a broadly applicable and consistent framework with which to explore the universal drivers of ecosystem structure and function (Heymans and others 2014; Link and others 2015).

Our understanding of ecosystems has come a long way from the simplified descriptions of food chains or Lotka-Volterra interactions. There is now a deeper appreciation of their vast complexity, which is characterized by a high degree of interlinked elements that interact on multiple scales. This holistic perspective incorporates the nonlinear processes, indirect effects, and emergent properties that play a major role in ecosystem behavior (Levin 1998). Ecosystems are hierarchal (Wu and David 2002), self-organizing networks (Jørgensen and others 1998), driven by the flow of energy and material (Reichle and others 1975). A central focus of this viewpoint emphasizes the philosophy that the whole is more than the sum of its parts and this depiction of ecosystems has shed light on the existence of a general set of driving principles among a seemingly endless sea of variables and unknowns (Odum 1969; Fath and others 2001).

Eugene P. Odum was one of the first scientists to look at ecosystems from a holistic point of view. By observing large-scale changes across ecosystems during successional events, he was able to identify general trends in productivity, biomass, and energy recycling over time (Odum 1969). He saw that ecosystems become bigger, more efficient, and more complex as they develop. The true significance of this study lies in Odum's introduction of the idea that one may not need to fully understand all of the intricate details and countless interactions of an ecosystem to predict how it will behave. Instead there may be a general set of rules or principles that drive ecosystem structure and function. Robert May and several other scientists took this a step further by identifying a number of mathematical guidelines (May 1973) governing the behavior of model food webs that relate their structure to functional aspects of stability and resilience across multiple systems (Margalef 1963). This work has led to a lot of research focusing upon the role of biodiversity in ecosystem functioning (Loreau and others 2001; Soliveres and others 2016). Scientists have developed several goal functions, or ecosystem orientors, that describe consistent multi-scale patterns of ecosystem development in terms of the flow of energy and material (Christensen 1995; Müller and others 1998; Fath and others 2004). These goal functions are mainly derived from Odum's initial observations of ecosystem development and make use of energy accounting and the basic laws of thermodynamics.

As support for the existence of general rules governing ecosystem structure and function continue to increase, the role of energy has emerged as a central component. Energy is one of the primary unifying characteristics of all life, from cells to ecosystems. Energy availability, extraction, and efficient use serve as major evolutionary driving forces (Lotka 1922). Due to this ubiquitous role, energy dynamics also provide a consistent framework for ecological comparisons (Ruiter and others 1995). This idea is certainly not new, and there are entire fields dedicated to the study of energy flow and storage within individuals and even ecosystems (Lindeman 1942; Townsend 1987). Using thermodynamic principles along with biogeochemical and bioenergetic data, it is now possible to analyze how much energy enters an ecosystem in the form of primary production, flows through it, and is stored as biomass into living organisms (Tomlinson and others 2014). In particular, satellite data (Smyth and others 2005) and trophic food web models (Fulton 2010; Colléter and others 2015) allow for the comparison of energetic inputs, outputs, and storages of entire ecosystems. A major advantage of this approach is that complexity and detail can be synthesized into summary indices that allow for the quantification of structure and function for any given ecosystem, and these characteristics can be compared across ecosystems at a global scale.

This study set out to identify global patterns in holistic properties of ecosystems: their size, efficiency, and complexity, to explore the existence of universal drivers of ecosystem structure and function. We used two approaches to measure energy flow and storage: (1) Satellite-derived values of net primary production (NPP) are compared with (2) a variety of energetic attributes extracted from ecosystem models representing 43 different marine 
ecosystems to identify general patterns. Satellite measures of NPP and indices derived from ecosystem models serve as completely independent data sources. From these comparisons, it is possible to identify consistent ecosystem-scale characteristics across a diverse set of systems, which not only shed light on the fundamental evolutionary processes of ecosystem development, but also may provide quantitative evidence for the existence of universal principles related to ecosystem-scale energy flow.

\section{MethoDS}

\section{Satellite Data}

NPP is defined in this study as the production derived from phytoplankton. Global estimates of NPP were obtained from the Centre for Environmental Data Analysis (CEDA) (Met Office 2017). The CEDA derived these data from monthly estimates of carbon primary production from the Centre for the Observation of Air-sea Interaction and fluXes (CASIX) using Sea-viewing Wide Field-of-view Sensor (SeaWiFS) Primary Data (Oreilly and others 1998). The data set used in this study is comprised of monthly means of NPP in $\mathrm{mgC}^{*} \mathrm{~m}^{-2 *} \mathrm{day}^{-1}$ for $10 \mathrm{~km} \times 10 \mathrm{~km}$ grid cells from 1998 to 2005 . The applied NPP model incorporates a radiative transfer code, which allows for the inclusion of dissolved organic matter and suspended particulate matter, along with measures of surface chlorophyll, photosynthetically available radiation, and sea surface temperature to calculate production (Smyth and others 2005). The incorporation of a radiative transfer into the NPP model improves global NPP estimates by increasing the accuracy of NPP estimates in waters with high concentrations of dissolved matter and reducing the RMS between observed and predicted values to 0.23 . However, moderate-resolution imaging spectroradiometer (MODIS) chlorophyll algorithms tend to overestimate dissolved organic matter in coastal waters, which can lead to an underestimation of primary production (Moore and others 2009).

\section{Ecosystem Models}

The ecosystem models selected for this study were developed using Ecopath with Ecosim (EwE) (Christensen and Pauly 1992; Pauly 2000). EwE is a software package that comprises several modules (Ecopath, Ecosim, and Ecospace) for building mass balance as well as time and space dynamic models of ecosystems and includes a large set of diagnostics for analyzing food webs. These features plus its flexibility and user-friendly interface make EwE one of the most widely applied modeling approaches for food web representation and scientific analysis (Walters and others 2005; Plagányi 2007). We used only the Ecopath component, a platform for building static ecological networks (that is, food webs) where network components are defined as functional groups (representing species or groups of species) and the interactions between components are trophic interactions quantified using bioenergetics (Christensen and Walters 2004). The major inputs for each component of the network include biomass, production and consumption rate, food preferences, unassimilated fraction, and fishing catches. Additional inputs include immigration, emigration, and biomass accumulation, while mortality and respiration are estimated by the model. Values for these parameters typically represent yearly averages over a small subset of years. Ecopath calculates a static mass-balanced snapshot of the biomass and energy fluxes between functional groups in a food web. The mass balance is set in a way that consumption of any given component is subtracted by all losses including bioenergetics ones (respiration, excretion), predation, eventual net migration, and mortality due to anthropogenic factors (that is, fishing). Remaining biomass can accumulate or result in an estimate of other mortalities unexplained by the model (summarized into the parameter Ecotrophic efficiency (Christensen and Walters 2004). A database of available EwE models is available through EcoBase (Colléter and others 2015).

Models were selected for use in this study based upon two general objectives. First, we constrained the influence of eutrophication and fishing effects. Information regarding the degree of eutrophication in ecosystem locations was provided by the World Resources Institute (WRI) (Selman and others 2008). The ratio of production to respiration (P/R) derived from Ecopath models represents the ratio of energy input to energy output in an ecosystem and might reflect the trophic status of a system. This was compared with WRI information to assure that local empirical and model-aggregated information was in agreement in spite of differences in resolution and spatial mean. Values of this ratio for systems with EwE models identified by the WRI as noneutrophic, all fell within a range of 1-3.5, whereas $88.9 \%$ of all systems identified by the WRI as eutrophic had values above this range. Therefore, any systems that were identified as eutrophic by the WRI or with a ratio of production to respiration above 3.5, were not selected for this study. The impact of fishing was limited by selecting model versions where fishing mortality was at its 
lowest for ecosystems with multiple model versions. (Complete removal was not possible.) For example, many ecosystems had two or more model versions representing different time periods with subsequently different commercial fishing pressures. When multiple model versions were available for different time periods, the period with the lowest fishing mortality across components was selected. Second, because model structure alters the simulated direct and indirect trophic impacts as well as subsequent energetic and organizational indices (Abarca-Arenas and Ulanowicz 2002), models with less than 20 components (or functional groups) were considered over-aggregated and not included in this study.

Once a suite of models was selected based upon the above criteria, a principle components analysis using synthetic ecosystem indices was conducted to identify any obvious outliers. Five models were identified and removed using the principle components analysis (PCA). A total of 43 Ecopath models met the requirements for inclusion (Appendix 2, ESM, and Figure 1), representing ecosystems spanning $130^{\circ}$ of latitude, and including all major ocean basins and a wide variety of ecosystem types, including 13 coastal ecosystems, three estuaries, two mid-ocean islands, five openocean ecosystems, one coral reef, 12 continental shelf ecosystems, and seven upwelling ecosystems.

\section{Ecosystem Indices and Definitions}

A total of 24 synthetic ecosystem indices were extracted from Ecopath models and explored (Appendix 1, ESM). Synthetic indices describing ecosystem-level properties related to macro-scale measures of ecosystem energy flow and storage as well as ecosystem structure and complexity characterize ecosystem-scale properties (combined measures of all ecosystem components), as opposed to specific properties (individual components or attributes at smaller scales within an ecosystem) (Christensen 1995; Müller and others 1998; Fath and others 2004). Each ecosystem index was compared with measures of mean NPP as well as seasonal and interannual variability in NPP. Although geographic location (high versus low latitude) and ecosystem type were also explored as potential drivers of observed patterns within these indices, preliminary results showed that neither played a significant role and there was no identifiable clustering of ecosystems by these variables in comparison with measures of NPP.

\section{Statistical Analyses}

For each ecosystem, monthly estimates of NPP $\left(\mathrm{mgC}^{*} \mathrm{~m}^{-2 *}\right.$ day $\left.^{-1}\right)$ per $1^{\circ}$ latitude by $1^{\circ}$ longitude grid cell were spatially averaged over a $10 \times 10$ grid cell area. Although the geographic extent of

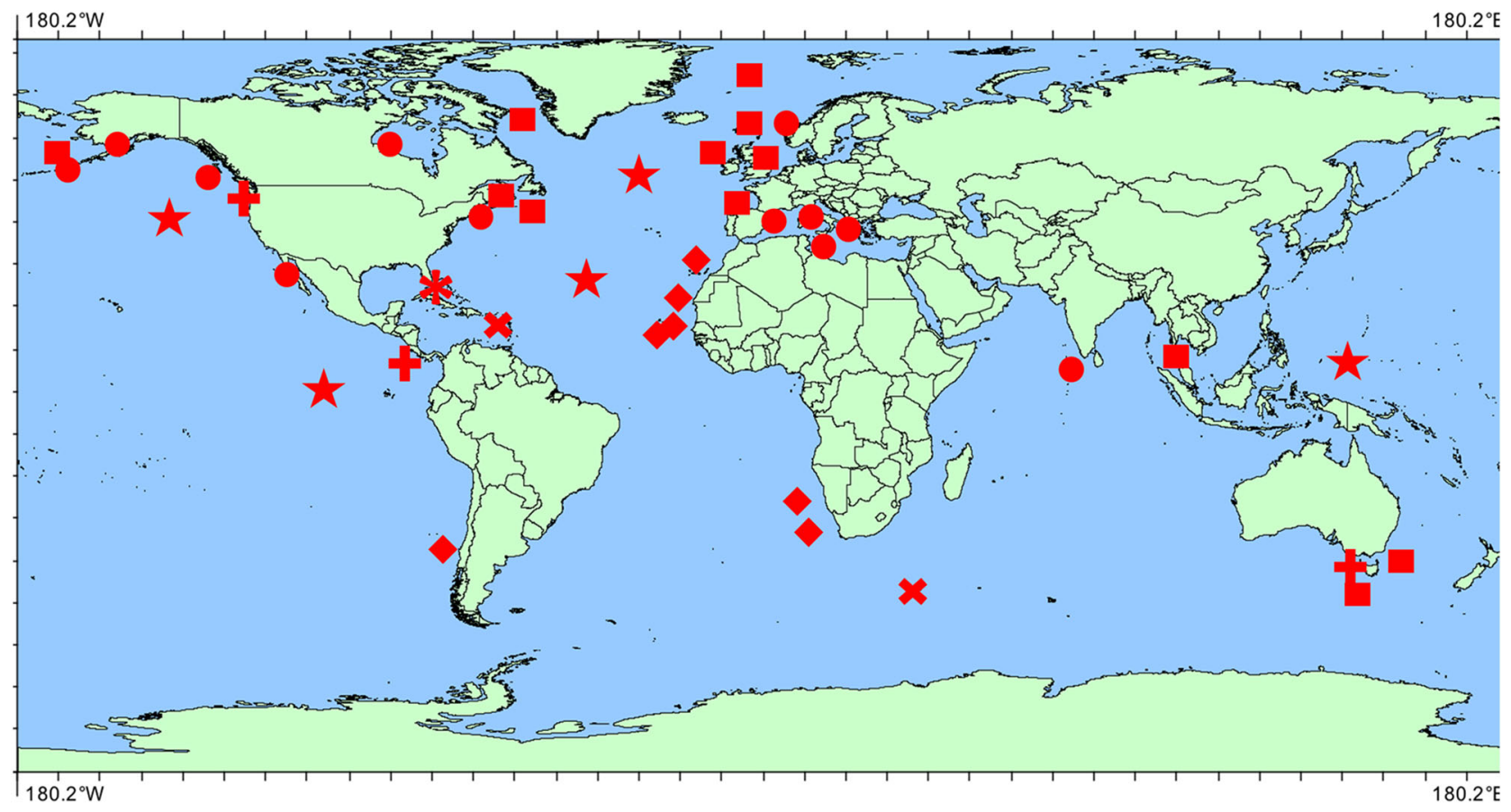

Figure 1. Global map of ecosystem locations differentiated by ecosystem type, selected for this study; coastal (circle), estuary $(+)$, island $(X)$, ocean (star), reef $(*)$, shelf (square), and upwelling (diamond). 
each ecosystem varied widely, we selected a $10 \times 10$ grid cell area within each ecosystem to control for those differences. The location of each sample area was chosen by using the latitude and longitude information provided by each ecosystem model to identify the ecosystem boundaries. For ecosystems that had much larger areas than $10 \times 10$ grid cells, latitude and longitude information was used to identify a central point, which was also designated as the center of the sample area. When explicit information regarding spatial dimensions of an ecosystem was missing, locations were determined by using respective maps found in model publications. Only marine cells were used for ecosystems adjacent to a coastline.

Monthly values of NPP were calculated over the period of available NPP estimates (1998-2005) to create time series for each ecosystem. Ecosystem indices were then compared with mean NPP (1998-2005 means) and interannual and seasonal variance in NPP. Interannual variance was calculated as the mean square (MS) of deviations between years, and seasonal variance was calculated as the mean square (MS) of deviations between months within a year. Regression models relating mean, and seasonal and interannual variability of NPP to each index were derived. In addition, due to a high degree of covariance in the MS of interannual and seasonal variability, both measures of temporal variability were simultaneously compared to each synthetic index; these are depicted in 3dimensional plots as multivariate regression surfaces. Moreover, because the use of mean squares of deviation to measure seasonal and interannual variability has the potential to introduce bias into the analysis because it generally correlates with the maximum productivity of an ecosystem, the entire analysis was also done using coefficients of variation (CV) for both seasonal and interannual variability. Model selection for both pairwise and 3dimensional comparisons between measures of NPP and ecosystem indices was conducted using Akaike's information criteria (AIC) and comparative $F$ tests. AIC values were chosen individually for mean NPP, seasonal, and interannual variability when doing pairwise comparisons for each index as well as for the combined seasonal and interannual variability 3D models. Within each category, several linear and polynomial models were created, and the lowest AIC value was used for selecting the model for each respective index. AIC values used for predictive model selection ranged between - 5.83 and 3.26. Random permutation tests were also conducted in order to estimate distributions of $r^{2}$ values extracted from randomly generated data sets, keeping the same polynomial models with newly fitted parameters.

The above analysis was also conducted using areas of $5 \times 5$ grid cells ( $5^{\circ}$ latitude by $5^{\circ}$ longitude) and $1 \times 1$ grid cell $\left(1^{\circ}\right.$ latitude by $1^{\circ}$ longitude) to identify the influence of spatial scale. Paired $t$ tests were used to compare mean NPP, MS of interannual variability, and MS of seasonal variability extracted using $1 \times 1,5 \times 5$, and $10 \times 10$ grid cell areas. All comparisons showed that spatial resolution did not significantly influence values of NPP extracted from each ecosystem location (minimum $p$ value of 0.053$)$. Two-dimensional KolmogorovSmirnov tests were also used to compare the relationships between ecosystem indices with NPP data extracted at different scales. All comparisons resulted in no statistical differences between relationships observed at each scale. Therefore, we present only results based on $10 \times 10$ grid cell areas.

\section{RESUlts}

Results were generally consistent between both absolute (MS) and relative (CV) measures of variability, suggesting that there was no significant difference and results with MS and CV were consistent for all ecosystem indices. For the sake of simplicity and synthesis, as well as to facilitate a more direct interpretation, the MS results are reported here. Of the 24 synthetic ecosystem indices explored, 8, listed below, displayed significant relationships $(P$ value $\leq 0.05)$ with satellite measures of mean NPP or its variability. (1) 'Biomass' represents the total wet weight of living organisms in the system (tons $/ \mathrm{km}^{2}$ ). Biomass serves as a measure of energy storage in an ecosystem. (2) 'Primary Production' (PP) refers to the amount of energy entering an ecosystem to be incorporated into biomass by autotrophs in tons $/ \mathrm{km}^{2} /$ year. PP serves as the major input of energy into an ecosystem. (3) 'Respiration' refers to the amount of energy leaving the system through metabolic processes in tons $/ \mathrm{km}^{2} /$ year and constitutes the major energetic output of ecosystems. (4) 'The ratio of Production to Biomass' (P/B) is a measure of how much production is needed to support each unit of biomass within an ecosystem. Production is expected to exceed respiration in immature ecosystems as biomass begins to accumulate, resulting in higher values (Winberg and others 1972). Lower values are expected in mature systems where the amount of biomass supported by available energy reaches a maximum and the majority of energy is used in maintenance. (5) 'The ratio of Biomass to 
Total System Throughput' (B/TST) is used as a measure of the amount of biomass maintained per unit of energy flowing through an ecosystem. Total system throughput represents the total flows of the ecosystem, including flows between ecosystem components and flows between the ecosystem and the exterior. The value of this ratio increases as ecosystems mature (Fath and others 2001). (6) 'Residence Time' is the mean time that a unit of energy remains in the system and is calculated as the total system biomass over the sum of all outputs (respiratory and export flows) from the system. Residence time is assumed to increase in mature systems as energy is efficiently retained in the system (Fath and others 2001). (7) 'Average Trophic Level' of the community is used to synthesize the structure of the food web and gives a general idea of system complexity. (8) 'Relative Ascendency' is an index of organization and complexity of a food web and is a useful ratio for observing where an ecosystem is along its developmental pathway. It represents the tradeoff between efficiency of energy flow (high ascendency) and redundancy in energy flow (system overhead) moving from primary producers to top predators in an ecosystem context (Monaco and Ulanowicz 1997). For example, a river delta would be considered a system with a low relative ascendency (high redundancy in pathways), whereas a single river channel would have a high relative ascendency (high efficiency of flow). Christensen (1995) found that relative ascendency had a very strong correlation with system maturity.

Mean NPP displayed weak relationships with most indices, with $r^{2}$ values below 0.1 for all but 2 of the 8 (Biomass and Average Trophic Level; Table 1). The very low $r^{2}$ associated with the relationship between mean NPP from satellite data and Primary Production from Ecopath models is likely due to the difference in source, timing of sampling, coverage, and temporal resolution of measures, although the analysis done using CV's resulted in a higher $r^{2}$. Unexpectedly, temporal variability of NPP (both seasonal and interannual) had stronger relationships than mean NPP for 7 of the 8 ecosystem indices (Table 1). With one exception (Average Trophic Level), $r^{2}$ values from regression models of seasonal and interannual variability with each index were larger (1.4-27 times larger) than model fits with mean NPP. Furthermore, relationships between each index and seasonal and interannual variability of NPP were independent of ecosystem type or latitude (Figure 2). $R^{2}$ values derived from multivariate relationships between both measures of variability and each ecosystem index were consistently higher than individual comparisons with either seasonal or interannual variability. $R^{2}$ values for these multivariate relationships ranged from 0.15 to 0.49 , and AIC values fell between -8.44 and 3.26 (Table 2).

Comparisons of the $\log$ of Biomass with mean NPP showed a weak, yet statistically significant $(P$ value $=0.0036)$, unimodal relationship $\left(r^{2}=0.18\right.$, $p=0.001)$. Stronger relationships were identified when compared to the MS of interannual and seasonal variability $\left(r^{2}=0.27\right.$ and $r^{2}=0.4$, respectively). The 3-dimensional multivariate model comparing Biomass with both modes of variability (Figure 2) has an $R^{2}$ value of 0.46 . When plotting each ecosystem data point in 3-dimensional space along the predictive surface, there was no identifiable clustering of systems based upon ecosystem type or latitude.

Three-dimensional relationships between Primary Production $\left(r^{2}=0.16\right)$ and Respiration $\left(r^{2}=.2\right)$ to interannual and seasonal variability displayed similar patterns to each other (Figure 3). Both showed strong positive increases with increasing seasonal variability and only a negligible response to interannual variability. Primary Production showed a weak relationship with mean NPP $(\rho=0.33, p=0.03)$; the relationship between Respiration and mean NPP was not significant.

$\mathrm{P} / \mathrm{B}\left(r^{2}=0.15\right), \mathrm{B} / \mathrm{TST}\left(r^{2}=0.19\right)$, and Residence Time $\left(r^{2}=0.14\right)$ all displayed similar unimodal patterns when compared to interannual and seasonal variability (Figure 4), but with $\mathrm{P} / \mathrm{B}$ having an opposite trend. $\mathrm{P} / \mathrm{B}$ was lowest at intermediate values of seasonal variation and higher at either extreme, whereas increasing interannual variability leads to minor increases in this ratio along the entire surface. The highest values for B/TST and Residence Time were observed at intermediate levels of seasonal variability. Increasing interannual variability had a minor positive influence at low values of seasonal variability and a minor negative influence at high values of seasonal variability. These indices did not display any significant relationships with mean NPP.

The 3-dimensional relationship between Relative Ascendency $\left(r^{2}=0.49\right)$ and variability (Figure 5) displayed a unimodal, valley-shaped pattern with the lowest values extending along the line of both increasing interannual and seasonal variability. The higher values extended along this valley at either extreme of interannual variability except when seasonal variability was also at its highest. The 3- 
Table 1. Relationships Between 8 Ecosystem Indices Derived from Ecopath with Ecosim and Net Primary Productivity (NPP) for 43 Marine Ecosystems

\begin{tabular}{|c|c|c|c|c|c|c|c|}
\hline \multirow[t]{2}{*}{ Index } & \multirow[t]{2}{*}{ Proxy for } & \multicolumn{2}{|c|}{ Mean NPP } & \multicolumn{2}{|c|}{$\begin{array}{l}\text { MS of seasonal } \\
\text { variability }\end{array}$} & \multicolumn{2}{|c|}{$\begin{array}{l}\text { MS of interannual } \\
\text { variability }\end{array}$} \\
\hline & & AIC & $r^{2}$ & AIC & $r^{2}$ & AIC & $r^{2}$ \\
\hline Biomass & Energy storage & -1.9122 & 0.1896 & -2.2098 & 0.3982 & -2.0121 & 0.2666 \\
\hline Primary Production & Energy input & -1.5957 & 0.0991 & -1.6635 & 0.1581 & -1.5655 & 0.0715 \\
\hline Respiration & Energy output & -1.696 & 0.088 & -1.8231 & 0.1968 & -1.7279 & 0.1568 \\
\hline Production/biomass (P/B) & Energy use efficiency & -2.3179 & 0.0137 & -2.4115 & 0.1427 & -2.331 & 0.0708 \\
\hline $\begin{array}{l}\text { Biomass/total system } \\
\text { throughput }(\mathrm{B} / \mathrm{TST})\end{array}$ & Energy use efficiency & -8.3934 & 0.0278 & -8.5053 & 0.1702 & -8.4265 & 0.1022 \\
\hline Residence time & Energy recycling & -5.8241 & 0.009 & -5.9111 & 0.133 & -5.8521 & 0.0802 \\
\hline Relative Ascendency & Structural complexity & 3.6726 & 0.0081 & 3.4713 & 0.189 & 3.4315 & 0.2206 \\
\hline Average Trophic Level & Structural complexity & -2.6699 & 0.2633 & -2.4172 & 0.0064 & -2.4759 & 0.063 \\
\hline
\end{tabular}

Mean, seasonal, and interannual (see text for details).

$M S=$ mean squares and $A I C=$ Akaike's information criteria

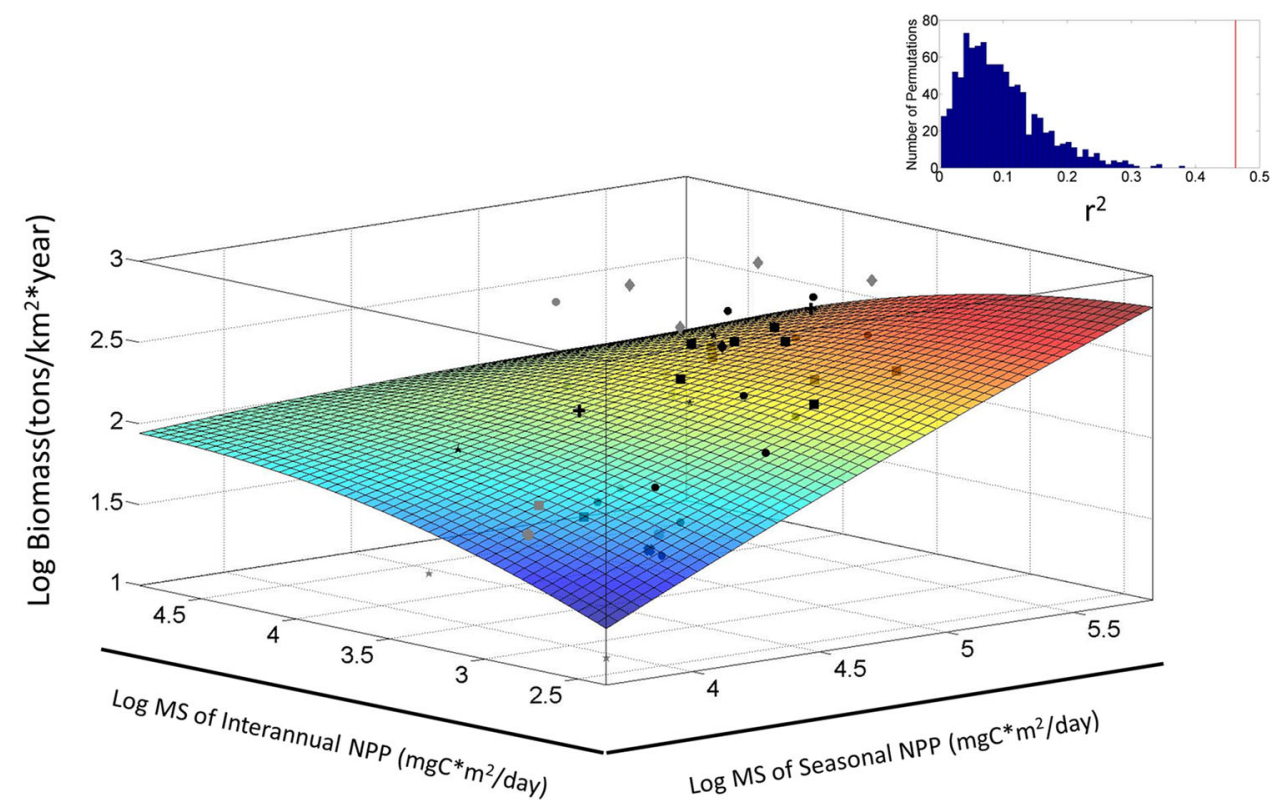

Figure 2. Relationships between ecosystem biomass and interannual and seasonal variability in net primary production $\left(r^{2}=0.46\right)($ AIC $=-2.2)$. Ecosystems $(n=43)$ located in higher latitudes $\left(\leq-30^{\circ}\right.$ and $\left.\geq 30^{\circ}\right)$ (black) and ecosystems located in lower latitudes $\left(\geq-30^{\circ}\right.$ and $\leq 30^{\circ}$ ) (gray) are separated by ecosystem type: coastal (circle), estuary $(+)$, island $(\mathrm{X})$, ocean (star), reef $(*)$, shelf (square), and upwelling (diamond). Histogram (top right) depicts $r^{2}$ distributions from a random permutation of model fits using randomized coefficients with the red line representing the model fit of the original data.

dimensional surface comparing the Average Trophic Level $\left(r^{2}=0.22\right)$ of each ecosystem with variability (Figure 5) displayed a strong positive relationship with increasing seasonal variability, while interannual variability had a negative influence. Both Relative Ascendency and Average Trophic Level did not show significant relationships with mean NPP.

\section{Discussion}

Limitation of the Approach and Uncertainty in Ecopath Modeling

The relationships identified here, although significant, have low $r^{2}$ values. This is not surprising when comparing things as complex as ecosystems, which involve a myriad of interacting 
Table 2. Multivariate Relationships Between Synthetic Ecosystem Indices and the MS of Interannual and Seasonal Variability Along with Their Respective Model AIC Values, the Number of Coefficients Used in Each Model, and $r^{2}$ Values

\begin{tabular}{lllll}
\hline Index & 3D model AIC & \# Model coefficients & Degrees of freedom & $r^{2}$ \\
\hline Biomass & -2.2 & 5 & 38 & 0.46 \\
Primary Production & -1.67 & 3 & 40 & 0.16 \\
Respiration & -1.78 & 3 & 40 & 0.20 \\
Production/biomass (P/B) & -2.32 & 5 & 38 & 0.15 \\
Biomass/total system throughput (B/TST) & -8.44 & 5 & 38 & 0.19 \\
Residence time & -5.83 & 5 & 38 & 0.14 \\
Relative Ascendency & 3.26 & 9 & 34 & 0.49 \\
Average Trophic Level & -2.61 & 3 & 40 & 0.22 \\
\hline
\end{tabular}
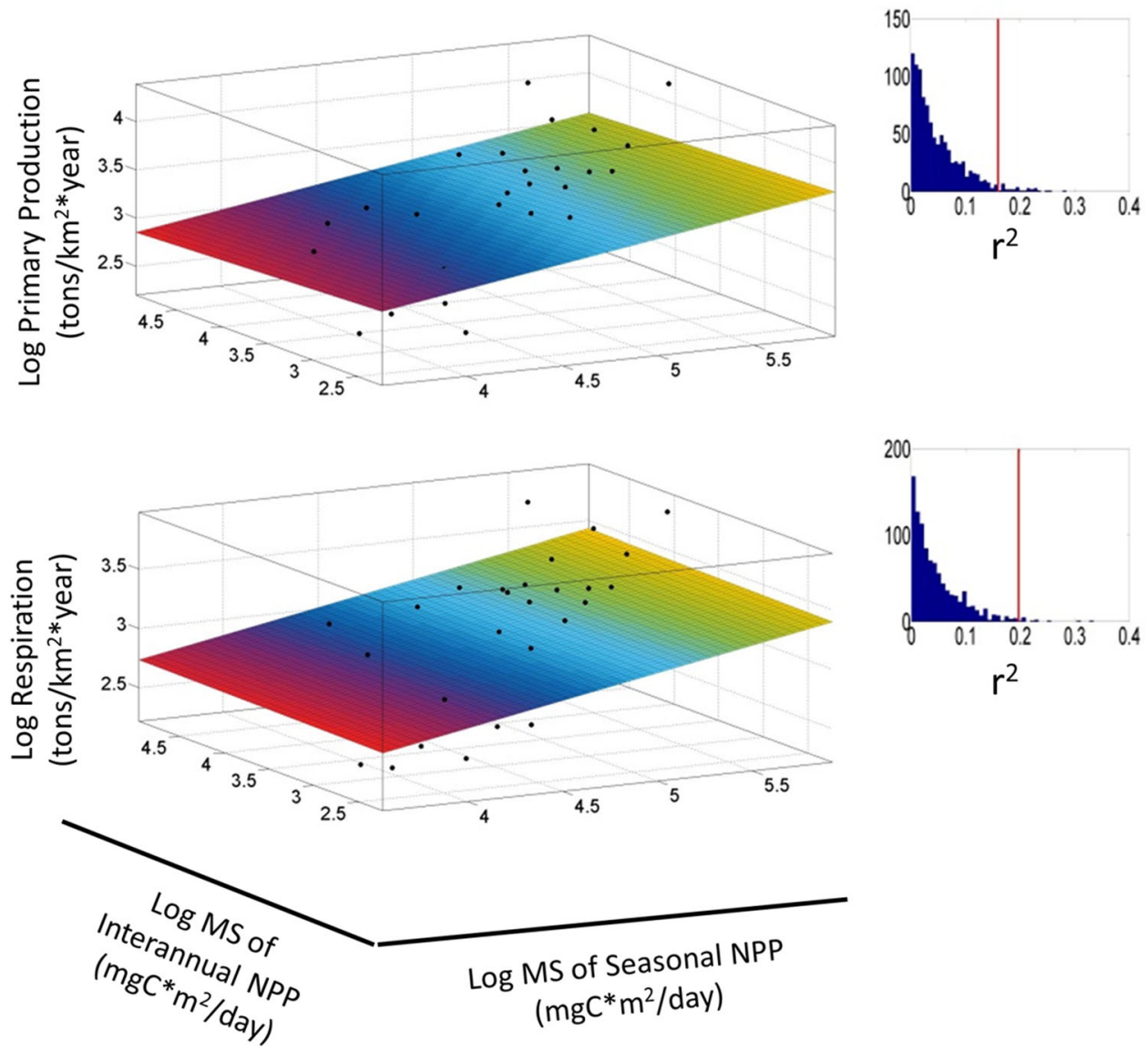

Figure 3. Relationships between interannual and seasonal variability in Net Primary Productivity (NPP) and Primary Production $\left(r^{2}=0.16\right)$ (AIC $\left.=-1.67\right)($ top $)$ and respiration $\left(r^{2}=0.2\right)(\mathrm{AIC}=-1.78)$ (bottom) estimates to measures of the $\log$ MS of interannual and seasonal variability in net primary production. Histograms as in Figure 2. Black dots denote ecosystem $(n=43)$ locations in variable space.

components and indirect effects. It is common, however, to observe low $r^{2}$ values for relationships comparing multiple ecosystems (Low-Décarie and others 2014) because of high ecological variability observed in natural systems. The ecosystem models allow for the synthesis of ecosystem complexity, including its variability across time, permitting simple comparisons of ecosystem properties. An important drawback of this approach is that observed relationships are strongly dependent on uncertainty of models used. 

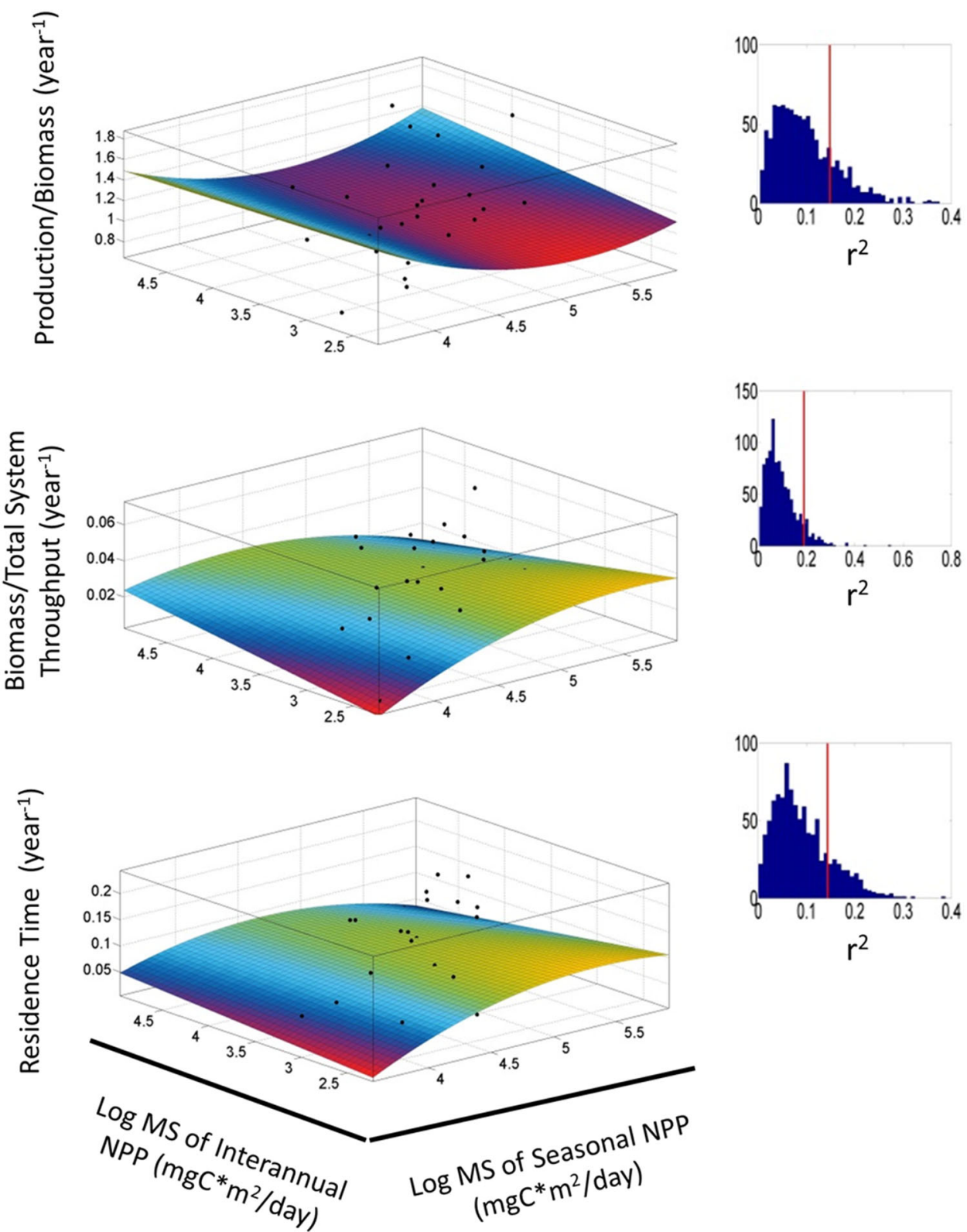

Figure 4. Relationships between interannual and seasonal variability in Net Primary Productivity (NPP) and P/B $\left(r^{2}=0.15\right) \quad(\mathrm{AIC}=-2.32) \quad($ top $), \mathrm{B} / \mathrm{TST}\left(r^{2}=0.19\right) \quad(\mathrm{AIC}=-8.44) \quad($ middle $)$, residence time $\left(r^{2}=0.14\right) \quad(\mathrm{AIC}=-5.83)$ (bottom) estimates to measures of the $\log$ MS of interannual and seasonal variability in net primary production. Histograms as in Figure 2. Black dots denote ecosystem $(n=43)$ locations in variable space.

Ecopath models are subject to the challenges of uncertainty faced by all ecosystem-scale modeling approaches that integrate extensive information and incorporate interactions between a wide variety of taxa. The abundance of model parameters, the aggregation chosen, and the scale of the model application can lead to the potential introduction and amplification of uncertainty. This challenge was partially addressed by removing Ecopath models vulnerable to significant sources of uncertainty, that is, only models with well-documented input parameter data sources, detailed in academic publications and reports, were selected. To reduce possible sources of bias, the selected models cover broad areas around the world and were each built independently by distinct teams of scientists and researchers. Furthermore, models with parameter distributions identified as outliers through principle component analyses were not selected. Anthropogenic influences on natural processes were also constrained by removing heavily fish- 

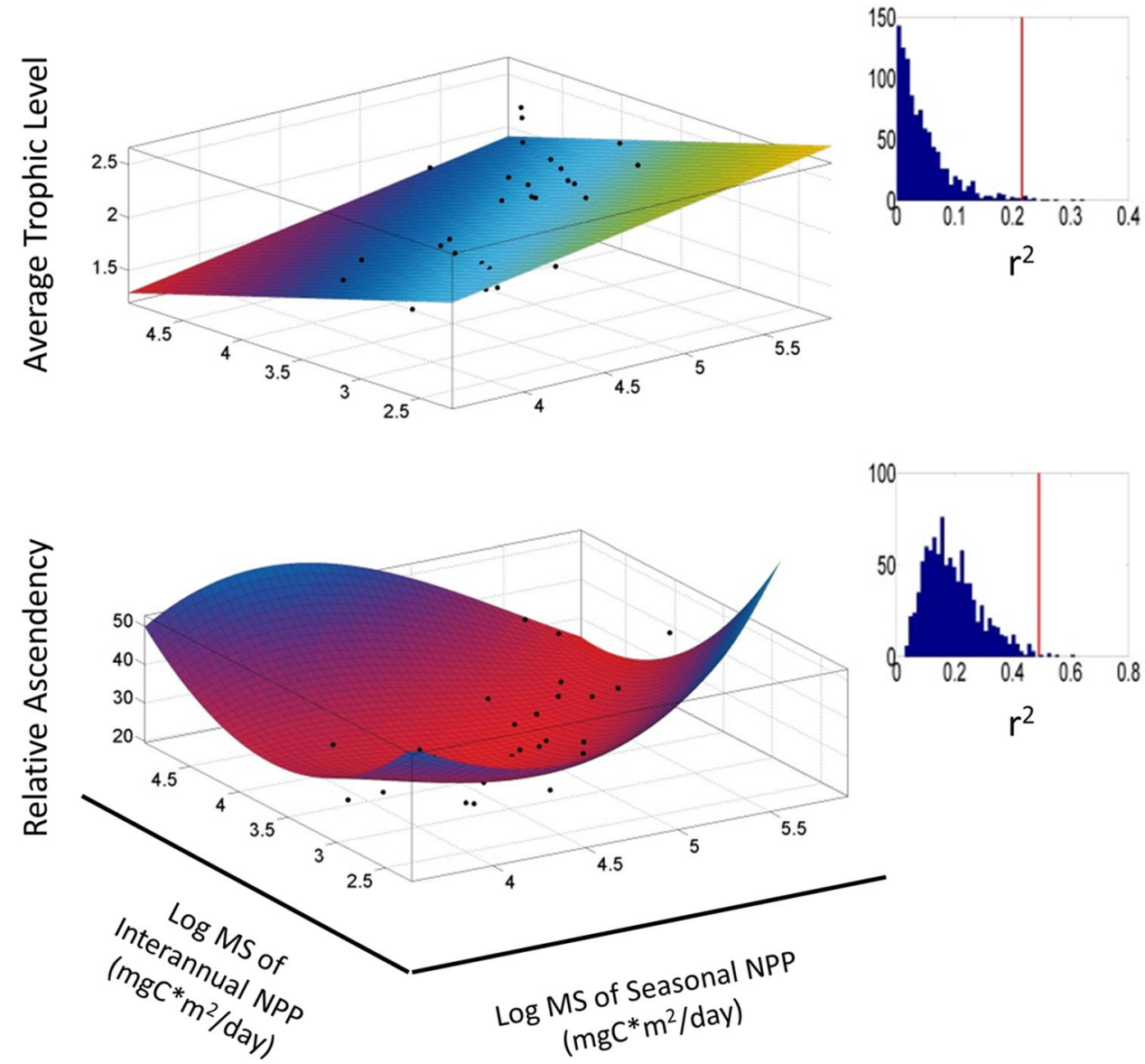

Figure 5. Relationships between interannual and seasonal variability in Net Primary Productivity (NPP) and Average Trophic Level (top) $\left(r^{2}=0.22\right)$ (AIC $\left.=-2.61\right)$ and Relative Ascendency $\left(r^{2}=0.49\right)$ (AIC $\left.=3.26\right)$ (bottom) estimates to measures of the log MS of interannual and seasonal variability in net primary production. Histograms as in Figure 2 . Black dots denote ecosystem $(n=43)$ locations in variable space.

eries-oriented ecosystems where possible or those exposed to significant levels of eutrophication.

Nevertheless, comprehensive ecosystem modeling would require field measurements and validation of all ecosystem rates and abundances in the same area over the same period of time, which involves extensive effort and resources to carry out. Because of these challenges, it is common to use empirical relationships, defined on the basis of species-specific relationships, to provide reliable estimates of yearly average rates (Pauly and Morgan 1987; Brey 1990; Middelburg and others 1997; Froese and Binohlan 2000), which might represent an inherent and unavoidable limitation of any ecosystem model (Plagányi 2007). Assuming that an ecosystem is the result of a series of adaptations to local seasonal and interannual variability, the steady state of the average year is a good representation of such adaptations. Analyzing ecosystem dynamics at finer timescales would require much more detailed data, which is not always available.

The complexity of Ecopath models, and the fact that some input parameters are estimated with low reliability, results in large uncertainty for some estimated values by functional groups. Ecotrophic efficiency is one such parameter that has been shown to be sensitive to uncertainty in Ecopath inputs (Essington 2007). However, the impact of uncertainty in input parameters on Ecopath model outputs has been addressed through the incorporation of Monte Carlo and other input parameter probability distribution methods into Ecopath and Ecosim (Kavanagh and others 2004) through which studies have found that parameter input combinations from Monte Carlo-derived models with the best fit to time series generally showed only slight changes from original base Ecopath model parameter inputs (averaging $\pm 20 \%$ ) 
(Shannon and others 2004; De Mutsert 2010; Li and others 2014). Nevertheless, this study does not directly use outputs for individual species and functional groups, but ecosystem-wide indicators. The influence of parameter uncertainty on synthetic ecosystem indices was tested in Guesnet and others (2015) for the Bay of Biscay, an Ecopath model used in this study. Through the introduction of uncertainty to Ecopath input parameters, this study assessed how estimates of ecosystem indices derived from the original Ecopath model inputs compared to output index distributions derived from varying levels of uncertainty. All ecosystem index values derived from the original base Ecopath model fell within subsequent index distributions following the incorporation of uncertainty. The results obtained by Guesnet and others (2015) suggest that ecosystem indices produced by Ecopath are not significantly affected by uncertainty in original ecosystem model input parameters below differences of $40 \%$ from true values.

Another consistent problem facing EwE ecosystem modeling is the lack of resolution and detail among lower trophic levels. This is likely representative of sampling bias and the ease of quantifying larger organisms versus microscopic communities, but also potentially due to bias introduced by model developers, which generally come from fisheries or high trophic level backgrounds. While Ecopath models tend to be fisheries oriented and many lack higher resolution among the lower trophic level groups, the major energy flows and storages of the whole ecosystem are, although aggregated, implicitly represented. As such, more resolution of high trophic levels compared to lower trophic levels does not directly influence the synthetic ecosystem indices presented (see, for example, Abarca-Arenas and Ulanowicz 2002; Angelini and Agostinho 2005). However, although the use of yearly averages for Ecopath input parameters is suitable for capturing high trophic level dynamics, it does not fully capture the smaller timescale variability of low trophic level populations. Although this, in turn, can influence estimates of model primary production, and therefore indirectly affects synthetic ecosystem indices, preliminary analyses showed a significant correlation between mean NPP from satellite data and Ecopath model estimates. Despite the potential indirect effects of overaggregation in lower trophic levels, preliminary analyses also showed that the total amount of functional groups across Ecopath models, which serves as a proxy for aggregation, were not significantly correlated with synthetic ecosys- tem indices and this is supported by previous studies (Heymans and others 2014).

In many instances, low trophic level flows are obtained from model estimates assuming average rates and biomasses (D'Alelio and others 2016) or imposing important measured flows and estimating the others on the basis of ecological maxima (or minima) for some ecosystem property (Middleburg and others 1997). Yet, the synthetic ecosystem indicators used in this study, and the relationships with variability, are not strongly driven by the overaggregation of low trophic level groups. To test this further, the analysis was redone with the removal of low trophic level groups. Ecosystem indices were recalculated across ecosystems, excluding the flows and biomasses of all plankton groups or any group with a trophic level of two or less. Results showed that the general shape of relationships between ecosystem indices calculated excluding lower trophic levels and measures of variability, although generally weaker, was maintained. The underlying patterns across ocean basins and different ecosystem types remained, and therefore, do not appear to be dependent on low trophic level groups. Results are thus supporting the fact that ecosystem-level organization is driving observed patterns.

Interannual variability might be less accurately represented in this study due to some of the largerscale temporal drivers of ecosystem change, such as multi-decadal oscillations, not being captured by the 8-year time series of NPP used here. This may explain why the influence of interannual variability was negligible for many of the observed relationships. As such, it is very possible that the relationships will only be strengthened by accounting for those larger temporal scales.

Despite uncertainty in Ecopath parameters and the temporal limitations of available NPP data, a major strength of our approach is the use of two independent data sets for our investigations of pattern: satellite-derived data and Ecopath model outputs. The measures of NPP that we used in our study are not used as input parameters in the construction of Ecopath models. Many of these models use in situ measurements of primary production, and while some may derive estimates of primary production from satellite data, variability in NPP is not used as an input in any way. Due to the number of ecosystem models used in this study and the consistency of global patterns identified across 8 different ecosystem indices when compared to a completely external data source, it is unlikely that the patterns found in this study are 
the result of a systematic error introduced through Ecopath.

\section{Role of Temporal Variability in NPP on Ecosystem-Scale Properties}

Our results provide insight into the general drivers of marine ecosystem structure and function. Total primary production is known to influence a wide variety of ecosystem-level properties including total production and biomass (Field 1998; Imhoff and others 2004), and biodiversity and food chain length (Costanza and others 2007). Few have compared the influence of temporal variation in primary production (Conti and Scardi 2010), but it is clearly significant. Our results show that ecosystem storage (Biomass) reaches maximum values at intermediate to high seasonal variability. Ecosystem output (Respiration) increases with seasonal variability of NPP. Ecosystem efficiency (a measure of internal recycling of energy or the amount of biomass supported by one or more energy flows, measured in this study by Residence Time, $\mathrm{P} / \mathrm{B}$, and $\mathrm{B} / \mathrm{TST}$ ), is also maximized at intermediate to high seasonal variability in NPP. The organizational complexity of ecosystems is strongly related to the temporal variability of NPP as well, with more efficient transfer of biomass through food chains (Average Trophic Level), and increased redundancy in pathways of biomass to top predators (Relative Ascendency) resulting from increased seasonal variability in NPP. It is important to note that although Relative Ascendency had the highest $r^{2}$ value of all synthetic indices, it also had the highest AIC values, suggesting potential overfitting of the data. Yet, given that temporal variation in NPP defines optimal storage and use of energy over time by component organisms in a given ecosystem, its influence on ecosystem structure and function is perhaps not so surprising (Landres and others 1999). Although the $r^{2}$ values for some of these relationships may seem low, when comparing multiple ecosystems, which are highly complex and involve a myriad of interacting components and indirect effects, it is common to observe low $r^{2}$ values (Low-Décarie and others 2014).

Although support for the influence of temporal variability in NPP on single properties of ecosystems (as opposed to indices that synthesize the state of an entire ecosystem) can be found throughout the literature, there is very little evidence for its influence on holistic ecosystem structure and function. For example, temporal variability in NPP drives the switch from small- to large-bodied planktonic communities (Dunne and others 2005), strongly impacts fisheries yield (Friedland and others 2012), and is positively correlated with the trophic level of fisheries at a global scale (Conti and Scardi 2010). However, this study quantifies the underlying holistic dynamics of energy flow related to a variety of ecosystem properties at a macro-scale, with the hope of combining previously qualitative observations with modern ecological theory. More importantly, we identified consistent global patterns across a variety of holistic ecosystem traits from extremely different ecosystems all related to a single variable, which has not been reported in the literature previously. Contrary to expectations, patterns of these synthetic indices with temporal variability of NPP were not clustered by geographic location or ecosystem type, suggesting that the influence of variability in NPP on ecosystem structure and function is potentially independent of major environmental factors or the magnitude of productivity regimes. The latter is supported by the weak relationships between synthetic indices and mean NPP. This work shows that variability in NPP simultaneously influences a variety of ecosystemlevel characteristics of energy flow that can be related to ecosystem efficiency, complexity, and scope. Very few individual variables have such farreaching consequences for holistic ecosystem structure and function. Furthermore, variability in NPP can be easily measured from satellites. As such, the identification of this relationship allows for a broad understanding and potential prediction of global ecosystem dynamics using minimal resources.

One potential mechanism explaining the influence of temporal variability of NPP on ecosystem structure and function may be related to functional diversity (the number of functionally disparate species within an ecosystem), which tends to be maximized under regimes of intermediate disturbance (Shea and others 2004). Although stable conditions can favor species-specific competitive advantages, disturbance can allow for the coexistence of competing species (that is, an increase in functional diversity) (Ward and Stanford 1983). Temporal variability in NPP can be thought of as change from a climatological mean and, in this way, analogous to a disturbance (Landres and others 1999). These subsequent changes allow for the coexistence of several energy pathways that are an expression of high functional diversity (D'Alelio and others 2016), which in turn influences ecosystem biomass (Török and others 2016). The strong positive relationship we found between Relative Ascendency, a measure of the number of diverse paths leading from primary producers to 
apex predators in a food web, and temporal variability in NPP provides support for this concept. The results of this study build upon previous literature linking biodiversity to ecosystem functioning (Soliveres and others 2016) by exploring the underlying energetic processes and identifying a potential mechanistic framework.

\section{Conclusion}

The field of systems ecology is progressing toward a consistent approach to understand and predict ecosystem structure and function (Jørgensen and others 2016) and the use of overarching synthetic indices, and emergent properties of ecosystem-scale energy flow have played a primary role in that advancement (Christensen 1995; Fath and others 2004; Heymans and others 2014; Link and others 2015). By using completely independent data sources (satellite measures of NPP and synthetic indices of structure and function from trophic food web models) this study builds upon past theoretical and empirical work by quantifying the role of ecosystem-scale energy input in explaining patterns of ecosystem structure and function. Our results highlight the utility of applying macro-scale dynamics of energy flow to understand and predict complex ecosystem behavior. These patterns are consistent across a wide range of temperatures, latitudes, and marine ecosystem types, linking diverse ecosystems together in a way that has not been previously identified. Although increasing the geographic range of sites by including more ecosystem models from underrepresented areas would increase the robustness of results, the findings of this study imply that despite complex evolutionary histories, species compositions, or environmental conditions, the temporal dynamics of NPP influence ecosystem properties in a way that is common to all marine ecosystems. Although more research needs to be conducted to truly identify the causal relationships behind these emergent ecosystem properties, energy flow and accounting provides a framework with which to potentially begin quantifying those mechanisms and this approach takes a step forward in that direction.

\section{OPEN ACCESS}

This article is distributed under the terms of the Creative Commons Attribution 4.0 International License (http://creativecommons.org/licenses/by/4 $.0 /$ ), which permits unrestricted use, distribution, and reproduction in any medium, provided you give appropriate credit to the original author(s) and the source, provide a link to the Creative Commons license, and indicate if changes were made.

\section{REFERENCES}

Abarca-Arenas L, Ulanowicz R. 2002. The effects of taxonomic aggregation on network analysis. Ecological Modelling 149:285-96.

Angelini R, Agostinho AA. 2005. Food web model of the Upper Paraná River Floodplain: description and aggregation effects. Ecological Modelling 181(2):109-21.

Brey T. 1990. Estimating productivity of macrobenthic invertebrates from biomass and mean individual weight. MEERESFORSCHUNG/REP. Marine Research 32(4):329-43.

Christensen V. 1995. Ecosystem maturity-towards quantification. Ecological Modelling 77(1):3-32.

Christensen V, Pauly D. 1992. ECOPATH II-a software for balancing steady-state ecosystem models and calculating network characteristics. Ecological Modelling 61(3):169-85.

Christensen V, Walters C. 2004. Ecopath with Ecosim: methods, capabilities and limitations. Ecological Modelling 172:109-39.

Colléter M, Valls A, Guitton J, Gascuel D, Pauly D, Christensen V. 2015. Global overview of the applications of the Ecopath with Ecosim modeling approach using the EcoBase models repository. Ecological Modelling 302:42-53.

Conti L, Scardi M. 2010. Fisheries yield and primary productivity in large marine ecosystems. Marine Ecology Progress Series $410: 233-44$.

Costanza R, Fisher B, Mulder K, Liu S, Christopher T. 2007. Biodiversity and ecosystem services: a multi-scale empirical study of the relationship between species richness and net primary production. Ecological Economics 61:478-91.

D'Alelio D, Libralato S, Wyatt T, Ribera d'Alcalà M. 2016. Ecological-network models link diversity, structure and function in the plankton food-web. Scientific Reports 6:2 1806. https://doi. org/10.1038/srep21806.

De Mutsert K. 2010. The effects of a freshwater diversion on nekton species biomass distributions, food web pathways, and community structure in a Louisiana estuary (Doctoral dissertation).

Dunne JP, Armstrong RA, Gnanadesikan A, Sarmiento JL. 2005. Empirical and mechanistic models for the particle export ratio. Global Biogeochemical Cycles. https://doi.org/10.1029/2004 GB002390.

Elton C. 1930. Notices of publications on animal ecology. The Journal of Ecology 18:166.

Essington T. 2007. Evaluating the sensitivity of a trophic massbalance model (Ecopath) to imprecise data inputs. Canadian Journal of Fisheries and Aquatic Sciences 64(4):628-37.

Fath B, Patten BC, Choi JS. 2001. Complementarity of ecological goal functions. Journal of theoretical biology 208(4):493-506.

Fath B, Jørgensen S, Patten B, Straškraba M. 2004. Ecosystem growth and development. Biosystems 77:213-28.

Field C. 1998. Primary production of the biosphere: integrating terrestrial and oceanic components. Science 281:237-40.

Friedland K, and others. 2012. Pathways between primary production and fisheries yields of large marine ecosystems. PLoS ONE 7:e28945.

Froese R, Binohlan C. 2000. Empirical relationships to estimate asymptotic length, length at first maturity and length at 
maximum yield per recruit in fishes, with a simple method to evaluate length frequency data. Journal of Fish Biology 56(4):758-73.

Fulton E. 2010. Approaches to end-to-end ecosystem models. Journal of Marine Systems 81:171-83.

Guesnet V, and others. 2015. Incorporating food-web parameter uncertainty into Ecopath-derived ecological network indicators. Ecological Modelling 313:29-40.

Heymans JJ, Coll M, Libralato S, Morissette L, Christensen V. 2014. Global patterns in ecological indicators of marine food webs: a modelling approach. PLoS ONE 9(4):e95845.

Imhoff $\mathrm{M}$, and others. 2004. Global patterns in human consumption of net primary production. Nature 429:870-873.

Irschick D, Fox C, Thompson K, Knapp A, Baker L, Meyer J. 2013. Functional ecology: integrative research in the modern age of ecology. Functional Ecology 27(1):1-4.

Jørgensen S, Mejer H, Nielsen S. 1998. Ecosystem as self-organizing critical systems. Ecological Modelling 111(2):261-8.

Jørgensen S, Nielsen S, Fath B. 2016. Recent progress in systems ecology. Ecological Modelling 319:112-18.

Kavanagh P, Newlands N, Christensen V, Pauly D. 2004. Automated parameter optimization for Ecopath ecosystem models. Ecological Modelling 172(2):141-9.

Landres P, Morgan P, Swanson F. 1999. Overview of the use of natural variability concepts in managing ecological systems. Ecological Applications 9:1179.

Levin S. 1995. The problem of pattern and scale in ecology. Ecological Time Series. 277:e326.

Levin SA. 1998. Ecosystems and the biosphere as complex adaptive systems. Ecosystems 1(5):431-6.

Li L, Pitcher T, Devlin R. 2014. Potential risks of trophic impacts by escaped transgenic salmon in marine environments. Environmental Conservation 42(02):152-61.

Lindeman R. 1942. The trophic-dynamic aspect of ecology. Ecology 23(4):399-417.

Link J, Pranovi F, Libralato S, Coll M, Christensen V, Solidoro C, Fulton E. 2015. Emergent properties delineate marine ecosystem perturbation and recovery. Trends in ecology $\delta$ evolution 30(11):649-61.

Loreau M, Naeem S, Inchausti P, Bengtsson J, Grime J, Hector A, Tilman D, and others. 2001. Biodiversity and ecosystem functioning: current knowledge and future challenges. Science 294(5543):804-808.

Lotka AJ. 1922. Contribution to the energetics of evolution. Proceedings of the National Academy of Sciences of the United States of America 8(6):147-151.

Low-Décarie E, Chivers C, Granados M. 2014. Rising complexity and falling explanatory power in ecology. Frontiers in Ecology and the Environment 12(7):412-18

Margalef R. 1963. On certain unifying principles in ecology. American Naturalist 97:357-74.

May R. 1973. Qualitative stability in model ecosystems. Ecology 54(3):638-41

Met Office Integrated Data Archive System (MIDAS) Land and Marine Surface Stations Data (1853-current). 2017. Centre for Environmental Data Analysis. http://badc.nerc.ac.uk/view/b adc.nerc.ac.uk_ATOM_dataent_ukmo-midas. Viewed on 12 Sep 2016.

Middelburg JJ, Soetaert K, Herman PM. 1997. Empirical relationships for use in global diagenetic models. Deep Sea Research Part I: Oceanographic Research Papers 44(2):327-44.
Monaco M, Ulanowicz R. 1997. Comparative ecosystem trophic structure of three US mid-Atlantic estuaries. Marine Ecology Progress Series 161:239-54.

Moore T, Campbell J, Dowell M. 2009. A class-based approach to characterizing and mapping the uncertainty of the MODIS ocean chlorophyll product. Remote Sensing of Environment 113(11):2424-30.

Müller F, Leupelt M, Reiche E, Breckling B. 1998. Targets, goals and orientors. In: Müller F, Leupelt M, Eds. Eco targets, goal functions, and orientors. Berlin: Springer. p 3-11.

Odum E. 1969. The strategy of ecosystem development. Science 164:262-70.

Oreilly J, Maritorena S, Mitchell B, Siegel D, Carder K, Garver S, Mcclain C, and others. 1998. Ocean color chlorophyll algorithms for SeaWiFS. Journal of Geophysical Research: Oceans 103(C 1 1): 24937-24953.

Pauly D. 2000. Ecopath, Ecosim, and Ecospace as tools for evaluating ecosystem impact of fisheries. ICES Journal of Marine Science 57:697-706.

Pauly D, Morgan GP. 1987. The theory and application of length-based methods of stock assessment. In: ICLARM Conference Series, Manila.

Plagányi E. 2007. Models for an ecosystem approach to fisheries (Food and Agriculture Organization of the United Nations, Rome). 1st Ed.

Reichle D, O'Neill R, Harris W. 1975. Principles of energy and material exchange in ecosystems. In: van Dobben WH, LoweMcConnel RH, Eds. Unifying concepts in ecology. Dordrecht: Springer. pp 27-43.

Ruiter P, Neutel A, Moore J. 1995. Energetics, patterns of interaction strengths, and stability in real ecosystems. Science 269(5228):1257.

Selman M, Greenhalgh S, Diaz R, Sugg Z. 2008. Eutrophication and hypoxia in coastal areas: a global assessment of the state of knowledge. World Resources Institute 284:1-6.

Shannon L, Christensen V, Walters C. 2004. Modelling stock dynamics in the southern Benguela ecosystem for the period 1978-2002. African Journal of Marine Science 26(1):179-96.

Shea K, Roxburgh S, Rauschert E. 2004. Moving from pattern to process: coexistence mechanisms under intermediate disturbance regimes. Ecology Letters 7:491-508.

Smyth TJ, Tilstone GH, Groom SB. 2005. Integration of radiative transfer into satellite models of ocean primary production. Journal of Geophysical Research. https://doi.org/10.1029/20 04JC002784.

Soliveres S, Van Der Plas F, Manning P, Prati D, Gossner M, Renner S, Birkhofer K, and others. 2016. Biodiversity at multiple trophic levels is needed for ecosystem multifunctionality. Nature 536(7617): 456-459.

Tomlinson S, and others. 2014. Applications and implications of ecological energetics. Trends in Ecology \& Evolution 29: 280290

Török P, and others. 2016. Functional diversity supports the biomass-diversity humped-back relationship in phytoplankton assemblages. Functional Ecology 30: 1593-1602.

Townsend C. 1987. Bioenergetics: linking ecology, biochemistry and evolutionary theory. Trends in Ecology $\&$ Evolution $2(1): 3-4$.

Walters C, Christensen V, Martell S, Kitchell J. 2005. Possible ecosystem impacts of applying MSY policies from single-species assessment. ICES Journal of Marine Science 62:558-68. 
Ward J, Stanford J. 1983. Intermediate-disturbance hypothesis: an explanation for biotic diversity patterns in lotic ecosystems. In: Fontaine III TD, Bartell SM, Eds. Dynamics of lotic systems. Ann Arbor (MI): Ann Arbor Science. pp 347-356.

Winberg GG, Babitsky VA, Gavrilov SI, Gladky GV, Zakharenkov IS, Kovalevskaya RZ, Mikheyeva TM, Nevyadomskaya PS, Ostapenya AP, Petrovich PG, Potenko JS, Yakushko OF. 1972.
Biological productivity of different types of lakes. In: Productivity problems of freshwaters. Warszawa-Krakow: PWN. pp 383-404.

Wu J, David J. 2002. A spatially explicit hierarchical approach to modeling complex ecological systems: theory and applications. Ecological Modelling 153(1):7-26. 